\title{
Relevance of suspicious lymph nodes in preoperative imaging for resectability, recurrence and survival of intrahepatic cholangiocarcinoma
}

Fabian Bartsch¹, Felix Hahn², Lukas Müller², Janine Baumgart', Maria Hoppe-Lotichius', ${ }^{1}$ Roman Kloeckner² and Hauke Lang ${ }^{1 *}$

\begin{abstract}
Background: Intrahepatic cholangiocarcinoma (ICC) is often diagnosed at an advanced stage resulting in a low resectability rate. Even after potentially curative resection the risk for tumor recurrence is high. Although the extent and value of lymphadenectomy is part of ongoing discussion, the role of preoperative imaging for assessment of suspicious lymph nodes (suspLN) has only been studied modestly. Aim of this study is to demonstrate the influence of suspicious lymph nodes in preoperative imaging on resectability, recurrence, and long-term outcome.

Methods: All patients who underwent exploration for ICC between January 2008 and June 2018 were included. Preoperative imaging (CT or MRI) was analysed with focus on suspLN at the hepatoduodenal ligament, lesser curvature, interaortocaval, and superior to the diaphragm; suspLN were classified according to the universally accepted RECIST 1.1 criteria; histopathology served as gold standard.

Results: Out of 187 patients resection was performed in 137 (73.3\%), in 50 patients the procedure was terminated after exploration. Overall, suspLN were found preoperatively in 73/187 patients (39\%). Comparing patients who underwent resection and exploration only, suspLN were significantly more common in the exploration group $(p=0.011)$. Regarding lymph node stations, significant differences could be shown regarding resectability: All tumors with suspLN superior to the diaphragm were irresectable. Preoperative imaging assessment showed a strong correlation with final histopathology, especially of suspLN of the hepatoduodenal ligament and the lesser curvature. Sensitivity of suspLN was $71.1 \%$, specificity 90.8\%. Appearance of tumor recurrence was not affected by suspLN $(p=0.289)$. Using a short-axis cut-off of $<>1 \mathrm{~cm}$, suspLN had significant influence on recurrence-free survival (RFS, $p=0.009$ ) with consecutive 1-, 3-, and 5-year RFS of 41, 21 , and $15 \%$ versus 29,0 , and $0 \%$, respectively. Similarly, 1 -, 3 - and 5 -year overall survival (OS) was 75,30 , and 18\% versus 59,18 , and $6 \%$, respectively $(p=0.040)$.

\footnotetext{
* Correspondence: hauke.lang@unimedizin-mainz.de

'Department of General, Visceral and Transplant Surgery, University Medical Center of the Johannes Gutenberg-University Mainz, Langenbeckst. 1, 55131 Mainz, Germany

Full list of author information is available at the end of the article
}

(c) The Author(s). 2020 Open Access This article is licensed under a Creative Commons Attribution 4.0 International License, which permits use, sharing, adaptation, distribution and reproduction in any medium or format, as long as you give appropriate credit to the original author(s) and the source, provide a link to the Creative Commons licence, and indicate if changes were made. The images or other third party material in this article are included in the article's Creative Commons licence, unless indicated otherwise in a credit line to the material. If material is not included in the article's Creative Commons licence and your intended use is not permitted by statutory regulation or exceeds the permitted use, you will need to obtain permission directly from the copyright holder. To view a copy of this licence, visit http://creativecommons.org/licenses/by/4.0/. The Creative Commons Public Domain Dedication waiver (http://creativecommons.org/publicdomain/zero/1.0/) applies to the data made available in this article, unless otherwise stated in a credit line to the data. 
(Continued from previous page)

Conclusion: Suspicious lymph nodes in preoperative imaging are predictor for unresectability and worse survival. Explorative laparoscopy should be considered, if distant suspicious lymph nodes are detected in preoperative imaging. Nevertheless, given a sensitivity of only $71.1 \%$, detection of suspicious lymph nodes in the preoperative imaging alone is not sufficient to allow for a clear-cut decision against a surgical approach.

Keywords: Intrahepatic cholangiocarcinoma, Cholangiocarcinoma, Preoperative imaging, Lymph node, recurrence, survival

\section{Background}

Harvesting of lymph nodes is established in many different malignancies and the 8th edition of the AJCC/UICC/TNM classification recommends a specific number of received lymph nodes per entity [1]. For intrahepatic cholangiocarcinoma (ICC) the importance and extension of lymphadenectomy is still in debate with a recommended number of six lymph nodes to be harvested currently. In different studies tumor positive lymph nodes had significant influence on long-term outcome [2-8]. In the recent literature factors regarding lymphadenectomy such as the total number of harvested lymph nodes, the number of malignant lymph nodes or positive LN to negative LN ratios are discussed extensively [9-11]. ICC is commonly diagnosed in an advanced tumor stage due to missing or late occurrence of symptoms. Complete resection offers the only chance of cure. The number of negative laparotomies and unresectability is high with resection rates of only 50 to $75 \%[7,8$, $12,13]$. Long-term outcome is determined by tumor recurrence, which is common in $40-76 \%$ of patients $[7,14,15]$. Precise prediction of resectability and/or prognosis is often difficult based on preoperative imaging. If extrahepatic spread is diagnosed, palliative treatment is initiated in most cases. If the ICC appears technically resectable, most often suspicious or borderline suspicious lymph nodes are discussed as lymph node metastasis have been shown to be highly predictive [16]. However, only a few publications regarding preoperative imaging and the aspect of lymph nodes are available for ICC. One study showed a positive predictive value for metastatic disease of $67 \%$ in round lymph nodes exceeding $18 \mathrm{~mm}$ which are rare [17]. Another study used positron emission tomography-computed tomography (PET-CT) and concluded that preoperative evaluation remains difficult [18] while a recent metaanalysis demonstrated PET-CT imaging to be accurate in the evaluation of primary tumors, lymph node and distant metastasis [19]. The most recent article found lymph node enlargement with a small axis diameter exceeding $1 \mathrm{~cm}$ in preoperative imaging as the strongest predictor for histopathological lymph node metastases [20].

Hence, the aim of this study is to analyse the preoperative imaging in four lymph node stations and the influence of suspLN on resectability, recurrence and long-term outcome.

\section{Methods}

All patients who underwent exploration because of ICC between January 2008 and June 2018 were prospectively collected in an institutional database and the data was transferred to SPSS 23 (SPSS Inc., released 2014, IBM SPSS Statistics for Windows, Version 23.0, IBM Armonk, NY, USA: IBM Corp). Patients with secondary liver malignancies as well as hepatocellular carcinoma, perihilar cholangiocarcinoma and gallbladder carcinoma were excluded. Further analyses were performed retrospectively and only patients with complete datasets were included.

All patients signed informed consent that data and follow-up will be collected anonymously and potentially used for scientific analysis. Regarding to the regulations of the federal state law (state hospital law \$36 \& \$37) and the independent ethics committee of RhinelandPalatinate, no ethical approval was necessary for this study. The work has been carried out in accordance with the Declaration of Helsinki.

\section{Preoperative evaluation and imaging}

For preoperative staging, we preferred contrast enhanced multiphasic computed tomography (CT). Many patients presented with the initial diagnosis already made at referring centers or in an ambulant setting. We accepted externally produced CT or magnetic resonance imaging (MRI) if it was of sufficient quality.

Lymph nodes were classified preoperatively as suspicious according to the original RECIST 1.1 criteria, the RECIST 1.1 amendment specifically designed for lymph node assessment and further supporting literature [21, 22]. Criteria applied to determine malignancy were first and foremost the size with a short-axis diameter $>1.5$ $\mathrm{cm}$ but also further ancillary imaging features such as spherical shape, no fatty hilus, strong contrast enhancement, MR-diffusion restriction, central necrosis, threshold growth and distribution pattern [23]. Examined lymph node stations were the hepatoduodenal ligament, retropancreatic, the lesser curvature, interaortocaval, and superior to the diaphragm. The axial diameter of the largest suspicious lymph node of each of the four stations was gathered. 


\section{Surgery, postoperative outcome and follow-up}

All explorations were performed by a group of experienced surgeons with special expertise in liver surgery. We have an aggressive attitude regarding resection at our center and perform visceral and vascular resections and reconstructions if reasonable to achieve complete tumor clearance. Suspicious lymph nodes were no reason to resign from resection if they were found in lymph node stations close to the liver. If suspicious lymph nodes were found distantly for example interaortocaval, several considerations were made regarding perioperative risk and constitution of the patient. In selected cases frozen section was performed, and if distant lymph node metastasis were detected we resigned from resection. Intra- and postoperative parameters were collected like type of resection, histological results, morbidity, mortality, and tumor recurrence. Lymphadenectomy was performed routinely in case of ICC at least in the hepatoduodenal ligament. After the new 8th edition of the UICC classification was published in 2017 lymphadenectomy was performed according to the included recommendations: for ICC of the right hepatic lobe lymphadenectomy contained the hepatoduodenal ligament, peripancreatic and periduodenal lymph nodes; for ICC of the left hepatic lobe lymphadenectomy contained the hepatoduodenal ligament and gastrohepatic lymph nodes [1]. Nevertheless, a small subset of patients had a $\mathrm{Nx}$ situation $(n=16)$. Although a lymphadenectomy was performed, no lymph nodes could be detected by the pathologist $(n=5)$. If hepatocellular carcinoma was suspected based on imaging, no lymphadenectomy was performed and the diagnosis of ICC was made through the final histology $(n=11)$.

Follow-up was conducted every 3 months after initial surgery for at least two years; later on the interval was increased to 6 months, if reasonable. CT or MR imaging was carried out at least every 6 months in turns with ultrasound examinations. If patients were not able to undergo follow-up at our center, for example because of logistic reasons, we stayed in contact with the treating physician to obtain all information needed. All patients signed informed consent for this kind of follow-up.

\section{Statistical analyses}

Categorical data was analysed using the $\mathrm{Chi}^{2}$ test in cross tabulation. Survival analyses were conducted with Kaplan-Meier curves and log rank test. A $p$-value of < 0.05 was considered significant. All analyses were intention-to-treat. Recurrence-free survival was defined according to Punt and colleagues [24].

\section{Results}

We report on 187 patients who underwent 137 resections (73.3\%) and 50 explorations. Patients' demographics, surgical characteristics and reasons for unresectability are provided in Table 1. Anatomical major resections were performed in $68.6 \%$. Morbidity after resection appeared in $38.7 \%$, the 90 -day mortality was $8 \%$.

Suspicious lymph nodes within the preoperative imaging were found in 74 cases $(39.6 \%)$ of the entire cohort. This divides further in 47 out of 137 patients $(34.3 \%)$ in the resection group and 27 out of 50 patients $(54 \%)$ in the exploration group which showed a statistically significant difference between these two groups $(p=0.015)$.

\section{Dissemination of suspicious lymph nodes and influence on resectability}

The dissemination of suspLN is shown in Table 2. Overall or in any analysed lymph node station the distribution of suspicious lymph nodes showed to be significantly influence resectability.

Comparing the influence on resectability for all five lymph node stations distinguished by size of the suspLN statistical significance is reached as well (Table 3). To demonstrate the amount of suspLN of the exploration group a ratio was calculated (suspLN exploration group/suspLN of lymph node station). The ratio raises analogously from the hepatoduodenal ligament with $36.8 \%$ (25/68), the lower curvature with $48.5 \%$ (16/33), retropancreatic with $52 \%$ (13/ $25)$, interaortocaval with $54.5 \%(12 / 22)$ to superior of the diaphragm with $100 \%(3 / 3)$.

\section{Suspicious lymph nodes in relation to final histopathological results}

A median of five lymph nodes were harvested (IQR 1-7, range 0-31) within the resection group and N0 status was achieved in 82 patients. In the final histopathological report, 39 patients were classified with $\mathrm{N} 1$ disease and 16 patients were classified $\mathrm{Nx}$ without any lymph nodes harvested. In correlation of suspLN through imaging and histopathologic result sensitivity was $71.1 \%$ and specificity $90.8 \%$. The presence of suspLN in preoperative imaging had a significant influence on the nodal status with a higher likelihood to have $\mathrm{N}+$ status, either for differentiation in suspLN present (or not) or different diameter of suspicious nodes $(p<$ 0.001 , each; see Table 4). Presence of suspLN had significant influence on nodal status for lymph nodes of the hepatoduodenal ligament $(p<0.001)$, retropancreatic $(p=0.011)$ and the lower curvature $(p=0.001)$, while interaortocaval lymph nodes had not $(p=0.540)$.

A correlation of clinicopathological parameters with suspLN and $\mathrm{N}$ status showed a significant influence of $\mathrm{T}$ and $\mathrm{N}$ status as well as UICC stage and suspLN ( $p<0.001$ each) as demonstrated in Table 5. Tumor size, multifocal disease and number of nodules had no significant effect. 
Table 1 Patients characteristics

\begin{tabular}{ll}
\hline All patients & $\boldsymbol{n}=187$ \\
\hline Age [Median, (IQR)] & $63.8(55.8-73.7)$ \\
Range & $32.3-84.4$ \\
Gender [Female / Male] & $93 / 94$ \\
ASA classification & \\
$\quad$ ASA I & 2 \\
ASA II & 79 \\
ASA III & 102 \\
ASA IV & 4 \\
Resections & $\mathbf{n}=137$ \\
Right trisectionectomy & 25 \\
Left trisectionectomy & 18 \\
Right hepatectomy & 22 \\
Left hepatectomy & 16 \\
Mesohepatectomy ${ }^{\text {a }}$ & 7 \\
ALPPS & 6 \\
Monosegmentectomy & 9 \\
Bisgementectomy & 23 \\
Resection of three liver sg. & 9 \\
Atypic / wedge resection & 2
\end{tabular}

\section{Vascular resections / reconstruction}

Portal vein / major liver vein / inferior vena cava

\section{Visceral resections / reconstruction}

Adren / Diaphragm / Duodenum / Stomach / Colon 4/9/1/1/1

\section{Histological outcome (8th edition of UICC classif.)}

$\begin{array}{ll}\text { T1a } & 22 \\ \text { T1b } & 30 \\ \text { T2 } & 54 \\ \text { T3 } & 12 \\ \text { T4 } & 19 \\ \text { No } & 82 \\ \text { N1 } & 39 \\ \text { NX } & 16 \\ \text { M0 } & 129 \\ \text { M1 }{ }^{b} & 8\end{array}$

RO 123

R1 14

G1 - well 3

G2 - moderate $\quad 85$

G3 - poor 38

G4 - undifferentiated 1

No grading - neoadjuvant therapy $\quad 10$

UICC la 14

UICC Ib 19

UICC ॥
Table 1 Patients characteristics (Continued)

\begin{tabular}{|c|c|}
\hline All patients & $\boldsymbol{n}=187$ \\
\hline UICC IIIa & 6 \\
\hline UICC IIIb & 41 \\
\hline UICC IV & 7 \\
\hline Cirrhosis & $9^{c}$ \\
\hline Unresectable & $n=50$ \\
\hline Peritoneal carcinomatosis & 19 \\
\hline Multifocal spread & 11 \\
\hline Cirrhosis & 3 \\
\hline small/impaired FLR ${ }^{d}$ & 7 \\
\hline Complex infiltration / advanced & 10 \\
\hline
\end{tabular}

Influence of suspicious lymph nodes on tumor recurrence and survival

Median overall survival (OS) of the resection group was 21.9 months with a consecutive 1-, 3- and 5-year OS of 72,28 , and $16 \%$, respectively.

Recurrence of any kind occurred in 90 patients $(65.7 \%)$ and suspLN in preoperative imaging had no influence on appearance of tumor recurrence $(p=0.289)$. Median recurrence-free survival (RFS) of the resection

Table 2 Dissemination of suspicious lymph nodes

\begin{tabular}{|c|c|c|c|c|}
\hline & $\begin{array}{l}\text { All } \\
\boldsymbol{n}=187\end{array}$ & $\begin{array}{l}\text { Resection group } \\
\boldsymbol{n}=137\end{array}$ & $\begin{array}{l}\text { Exploration group } \\
\boldsymbol{n}=50\end{array}$ & $\boldsymbol{p}$-value \\
\hline \multicolumn{5}{|c|}{ Suspicious lymph nodes $^{a}$} \\
\hline Yes & $74(39.6 \%)$ & $47(34.3 \%)$ & $27(54 \%)$ & 0.015 \\
\hline No & $113(60.4 \%$ & $90(65.7 \%)$ & $23(46 \%)$ & \\
\hline \multicolumn{5}{|c|}{ SuspLN hepatoduodenal lig. } \\
\hline Yes & $68(36.4 \%)$ & $43(31.4 \%)$ & $25(50 \%)$ & 0.019 \\
\hline No & $119(63.6 \%)$ & $94(68.6 \%)$ & $25(50 \%)$ & \\
\hline \multicolumn{5}{|c|}{ SuspLN retropancreatic } \\
\hline Yes & $25(13.4 \%)$ & $12(8.8 \%)$ & $13(26 \%)$ & 0.002 \\
\hline No & $162(86.6 \%)$ & $125(91.2 \%)$ & $37(74 \%)$ & \\
\hline \multicolumn{5}{|c|}{ SuspLN lower curvature } \\
\hline Yes & $33(17.6 \%)$ & $17(12.4 \%)$ & $16(32 \%)$ & 0.002 \\
\hline No & $154(82.4 \%)$ & $120(87.6 \%)$ & $34(68 \%)$ & \\
\hline \multicolumn{5}{|c|}{ SuspLN interaortocaval } \\
\hline Yes & $22(11.8 \%)$ & $10(7.3 \%)$ & $12(24 \%)$ & 0.002 \\
\hline No & $165(88.2 \%)$ & $127(92.7 \%)$ & $38(76 \%)$ & \\
\hline \multicolumn{5}{|c|}{ SuspLN supradiaphragmal } \\
\hline Yes & $3(1.6 \%)$ & $0(-)$ & $3(6 \%)$ & 0.004 \\
\hline No & 184 (98.4\%) & 137 (100\%) & 47 (94\%) & \\
\hline
\end{tabular}


Table 3 Distribution of suspicious lymph nodes distinguished by size

\begin{tabular}{|c|c|c|c|c|}
\hline & All & Resection group & Exploration group & $\boldsymbol{p}$-value \\
\hline All LN stations together & $n=935^{a}$ & $n=685$ & $n=250$ & \\
\hline No suspicious LN & 784 (83.9\%) & $603(88 \%)$ & $181(72.4 \%)$ & \\
\hline$<1 \mathrm{~cm}$ & $63(6.7 \%)$ & $39(5.7 \%)$ & $24(9.6 \%)$ & \\
\hline $1-1.5 \mathrm{~cm}$ & $71(7.6 \%)$ & 37 (5.4\%) & $34(13.6 \%)$ & \\
\hline$>1.5 \mathrm{~cm}$ & $17(1.8 \%)$ & $6(0.9 \%)$ & $11(4.4 \%)$ & \\
\hline Hepatoduodenal lig. & $n=187$ & $n=137$ & $n=50$ & \\
\hline No suspicious LN & $119(63.6 \%)$ & $94(68.6 \%)$ & $25(50 \%)$ & $p=0.001$ \\
\hline$<1 \mathrm{~cm}$ & $22(11.8 \%)$ & $18(13.1 \%)$ & $4(8 \%)$ & \\
\hline $1-1.5 \mathrm{~cm}$ & $33(17.6 \%)$ & $21(15.3 \%)$ & $12(24 \%)$ & \\
\hline$>1.5 \mathrm{~cm}$ & $13(7 \%)$ & $4(3 \%)$ & $9(18 \%)$ & \\
\hline Retropancreatic & $n=187$ & $n=137$ & $n=50$ & \\
\hline No suspicious LN & $162(86.6 \%)$ & $125(91.3 \%)$ & 37 (74\%) & $p=0.009$ \\
\hline$<1 \mathrm{~cm}$ & $9(4.8 \%)$ & $4(2.9 \%)$ & $5(10 \%)$ & \\
\hline $1-1.5 \mathrm{~cm}$ & $16(8.6 \%)$ & $8(5.8 \%)$ & $8(16 \%)$ & \\
\hline$>1.5 \mathrm{~cm}$ & - & - & - & \\
\hline Lower curvature & $n=187$ & $n=137$ & $n=50$ & \\
\hline No suspicious LN & $154(82.3 \%)$ & $120(87.6 \%)$ & $34(68 \%)$ & $p=0.009$ \\
\hline$<1 \mathrm{~cm}$ & $16(8.6 \%)$ & $9(6.6 \%)$ & $7(14 \%)$ & \\
\hline $1-1.5 \mathrm{~cm}$ & $16(8.6 \%)$ & $7(5.1 \%)$ & $9(18 \%)$ & \\
\hline$>1.5 \mathrm{~cm}$ & $1(0.5 \%)$ & $1(0.7 \%)$ & - & \\
\hline Interaortocaval & $n=187$ & $n=137$ & $n=50$ & \\
\hline No suspicious LN & 165 (88.2\%) & $127(92.7 \%)$ & $38(76 \%)$ & $p=0.004$ \\
\hline$<1 \mathrm{~cm}$ & $14(7.5 \%)$ & $8(5.9 \%)$ & $6(12 \%)$ & \\
\hline $1-1.5 \mathrm{~cm}$ & $6(3.2 \%)$ & $1(0.7 \%)$ & $5(10 \%)$ & \\
\hline$>1.5 \mathrm{~cm}$ & $2(1.1 \%)$ & $1(0.7 \%)$ & $1(2 \%)$ & \\
\hline Supradiaphragmal & $n=187$ & $n=137$ & $n=50$ & \\
\hline No suspicious LN & $184(98.4 \%)$ & $137(100 \%)$ & 47 (94\%) & $p=0.015$ \\
\hline$<1 \mathrm{~cm}$ & $2(1.1 \%)$ & - & $2(4 \%)$ & \\
\hline $1-1.5 \mathrm{~cm}$ & - & - & - & \\
\hline$>1.5 \mathrm{~cm}$ & $1(0.5 \%)$ & - & $1(2 \%)$ & \\
\hline
\end{tabular}

${ }^{a}$ Five lymph node stations per 187 patients

group was 9.7 months with a consecutive 1-, 3-, and 5year RFS of 38,16 , and $12 \%$, respectively.

\section{Recurrence-free survival}

If recurrence-free survival (RFS) is calculated for positive versus negative suspLN no significant difference can be detected $(p=0.158)$. If a cut-off of $1 \mathrm{~cm}$ is applied, the group without suspLN had significantly better RFS compared to the $>1 \mathrm{~cm}$ group ( $p=0.008$; Fig. 1$)$ with medians of 10.2 versus 8.4 months and a consecutive 1-, 3and 5 -year RFS of 41,21 , and $15 \%$ versus 29,0 , and $0 \%$, respectively. Further subgroup analyses of the different lymph node stations showed no significant difference except the hepatoduodenal ligament $(p=0.036)$.

\section{Overall survival}

In analyses of OS, no difference can be shown for positive versus negative suspLN $(p=0.252)$ and different size categories $(p=0.067)$. Using a cut-off of $1 \mathrm{~cm}$, median OS was 23.1 months versus 16.2 months with consecutive 1 -, 3 - and 5 -year OS of 75, 30, and $18 \%$ versus 59, 18 , and $6 \%$, respectively ( $p=0.026$; Fig. 2$)$. In further subgroup analyses for OS of the different lymph node stations with a $1 \mathrm{~cm}$ cut-off the hepatoduodenal ligament $(p=0.020)$ and retropancreatic $(p<0.001)$ were significantly different.

\section{Discussion}

In this study we were able to show that suspLN in specific lymph node stations make irresectability more likely 
Table 4 Relation of preoperative imaging and histopathological nodal status

\begin{tabular}{|c|c|c|c|c|c|}
\hline \multicolumn{6}{|l|}{ All lymph node stations } \\
\hline Suspicious nodes & $\mathrm{n}$ & N1 & NO & $\mathrm{N} 1 / \mathrm{NO}^{\mathrm{a}}$ & \multirow{4}{*}{$\mathrm{p}<0.001$} \\
\hline No & $76(62.8 \%)$ & $7(17.9 \%)$ & $69(84.1 \%)$ & 0.10 & \\
\hline$<1 \mathrm{~cm}$ & $17(14 \%)$ & $9(23.1 \%)$ & $8(9.8 \%)$ & 1.13 & \\
\hline $1-1.5 \mathrm{~cm}$ & $22(18.2 \%)$ & $18(46.2 \%)$ & $4(4.9 \%)$ & 4.5 & \\
\hline$>1.5 \mathrm{~cm}$ & $6(5 \%)$ & $5(12.8 \%)$ & $1(1.2 \%)$ & 5 & \\
\hline No suspicious nodes & $76(62.8 \%)$ & $7(17.9 \%)$ & $69(84.1 \%)$ & 0.10 & $p<0.001$ \\
\hline Suspicious nodes (any size) & $45(37.2 \%)$ & $32(82.1 \%)$ & $13(15.9 \%)$ & 2.5 & \\
\hline \multicolumn{6}{|l|}{ Hepatoduodenal ligament } \\
\hline Suspicious nodes & $\mathbf{n}$ & N1 & No & N1/No ${ }^{a}$ & \multirow{5}{*}{$\mathrm{p}<0.001$} \\
\hline No & 79 (65.3\%) & $9(23.1 \%)$ & $70(85.3 \%)$ & 0.13 & \\
\hline$<1 \mathrm{~cm}$ & $17(14 \%)$ & $9(23.1 \%)$ & $8(9.8 \%)$ & 1.13 & \\
\hline $1-1.5 \mathrm{~cm}$ & $21(17.4 \%)$ & $17(43.5 \%)$ & $4(4.9 \%)$ & 4.25 & \\
\hline$>1.5 \mathrm{~cm}$ & $4(3.3 \%)$ & $4(10.3 \%)$ & - & 4 & \\
\hline \multicolumn{6}{|l|}{ Retropancreatic } \\
\hline Suspicious nodes & $\mathrm{n}$ & N1 & NO & $\mathrm{N} 1 / \mathrm{NO}^{\mathrm{a}}$ & \multirow{5}{*}{$p=0.011$} \\
\hline No & 110 (90.9\%) & $31(79.5 \%)$ & 79 (86.3\%) & 0.39 & \\
\hline$<1 \mathrm{~cm}$ & $4(3.3 \%)$ & $3(7.7 \%)$ & $1(1.2 \%)$ & 3 & \\
\hline $1-1.5 \mathrm{~cm}$ & 7 (5.8\%) & $5(12.8 \%)$ & $2(2.4 \%)$ & 2.5 & \\
\hline$>1.5 \mathrm{~cm}$ & - & - & - & $x$ & \\
\hline \multicolumn{6}{|l|}{ Lower curvature } \\
\hline Suspicious nodes & $n$ & N1 & No & $\mathrm{N} 1 / \mathrm{NO}^{\mathrm{a}}$ & \multirow{5}{*}{$p=0.001$} \\
\hline No & 105 (86.8\%) & $26(66.6 \%)$ & 79 (86.3\%) & 0.33 & \\
\hline$<1 \mathrm{~cm}$ & $8(6.6 \%)$ & $6(15.4 \%)$ & $2(2.4 \%)$ & 3 & \\
\hline $1-1.5 \mathrm{~cm}$ & 7 (5.8\%) & $6(15.4 \%)$ & $1(1.2 \%)$ & 6 & \\
\hline$>1.5 \mathrm{~cm}$ & $1(0.8 \%)$ & $1(2.6 \%)$ & - & $x$ & \\
\hline \multicolumn{6}{|l|}{ Interaortocaval } \\
\hline Suspicious nodes & $\mathrm{n}$ & N1 & No & $\mathrm{N} 1 / \mathrm{NO}^{\mathrm{a}}$ & \multirow{5}{*}{$p=0.540$} \\
\hline No & $112(92.6 \%)$ & $34(87.1 \%)$ & 78 (95.1\%) & 0.44 & \\
\hline$<1 \mathrm{~cm}$ & $7(5.8 \%)$ & $4(10.3 \%)$ & $3(3.7 \%)$ & 1.33 & \\
\hline $1-1.5 \mathrm{~cm}$ & $1(0.8 \%)$ & $1(2.6 \%)$ & - & $x$ & \\
\hline$>1.5 \mathrm{~cm}$ & $1(0.8 \%)$ & - & $1(1.2 \%)$ & $x$ & \\
\hline
\end{tabular}

NX patients were excluded $(n=16) ;{ }^{a}$ ratio between positive and negative nodal status ( $X$ if ratio is mathematically not possible)

showing a significant relationship. Especially all tumors with suspLN superior to the diaphragm were irresectable, even if the number was small $(n=3)$. SuspLN within the hepatoduodenal ligament, retropancreatic or the lesser curvature were significantly associated with histopathological positive lymph node status. Sensitivity of suspLN was $71.1 \%$ and specificity $90.8 \%$. An association of suspLN and tumor recurrence of any kind could not be shown. Using a cut-off of $1 \mathrm{~cm}$ short-axis diameter, suspLN had a significant influence on RFS and OS.

ICC is the second most common primary malignant tumor of the liver and often diagnosed in an advanced tumor stage due to a late onset of symptoms. The number of negative laparotomies varies depending on the aggressiveness of each surgical team, but is still high with $25-50 \%[7,8,12,25]$. To spare patients of this dilemma, a better preoperative evaluation with a precise assessment of resectability is essential. R0-resection remains the only chance of cure, but extrahepatic spread and often lymphatic spread is an obvious reason to resign from surgery. The preoperative evaluation of lymph nodes through imaging is always a vivid discussion in interdisciplinary tumor conferences regarding possibility and reasonableness of resection. We have an aggressive attitude towards resections to offer most patients the chance of complete tumor removal. If major or extended resections were performed in cases with suspected distant lymph node metastases was based on multiple 
Table 5 Clinicopathological parameters in correlation with suspLN and N status

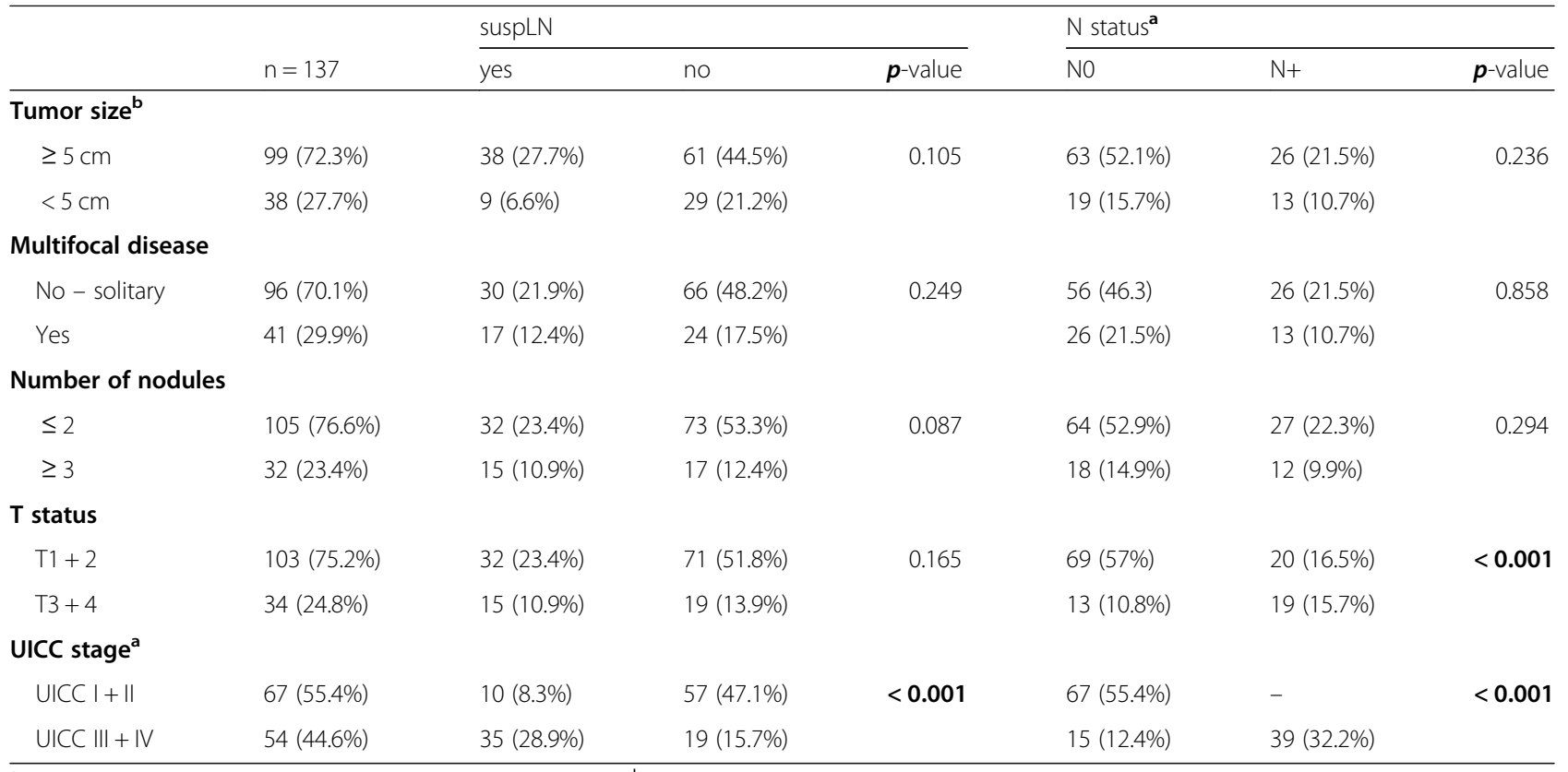

${ }^{a}$ NX patients were excluded $(n=16)$ or UICC was not applicable; ${ }^{\text {b }}$ diameter of largest nodule

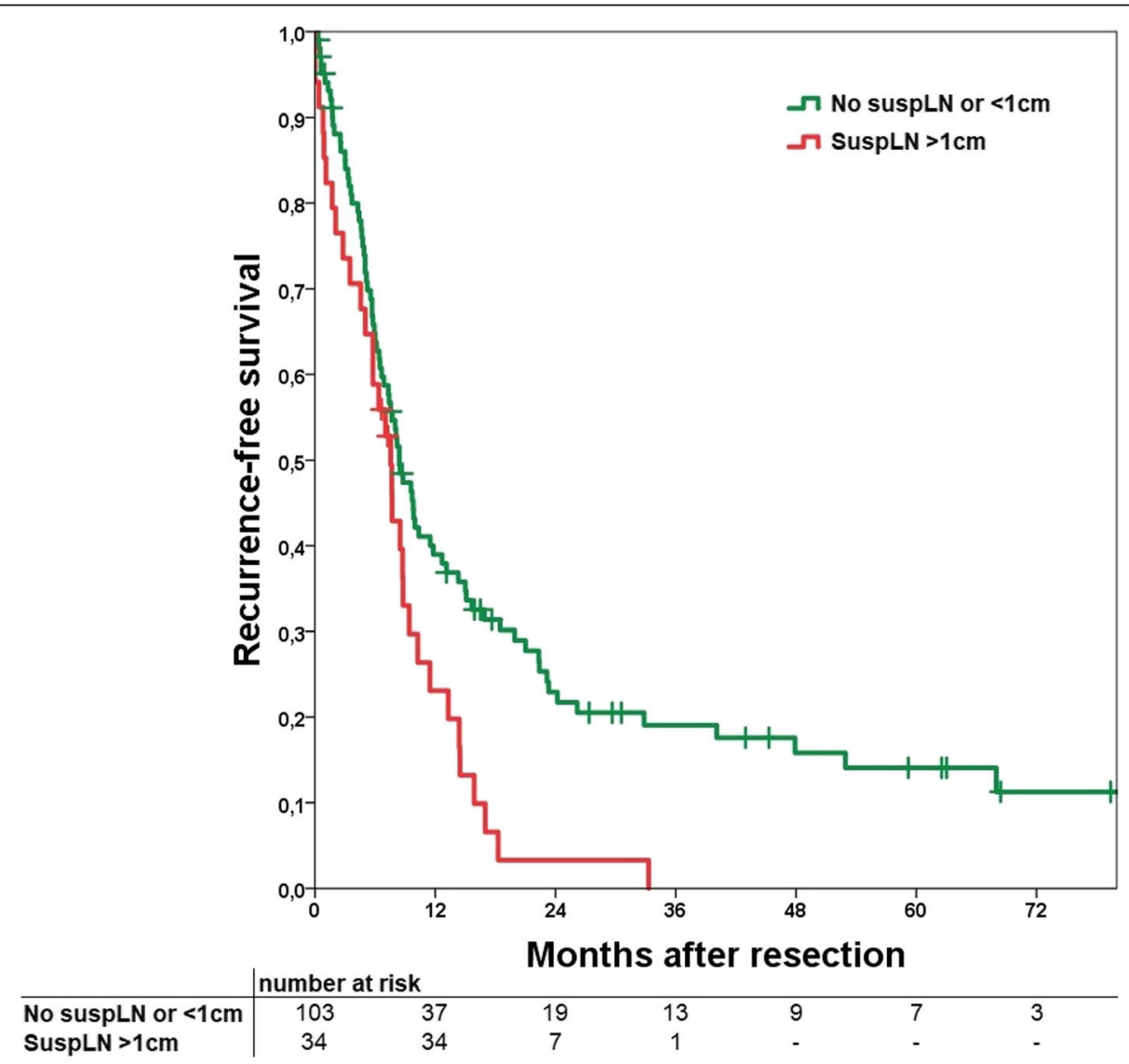

Fig. 1 Kaplan-Meier curve of recurrence-free survival comparing a group of no suspicious lymph nodes or a diameter $<1 \mathrm{~cm}$ (No suspLN or $<1$ $\mathrm{cm}$ ) and suspicious lymph nodes with a diameter $>1 \mathrm{~cm} . p=0.008$ 


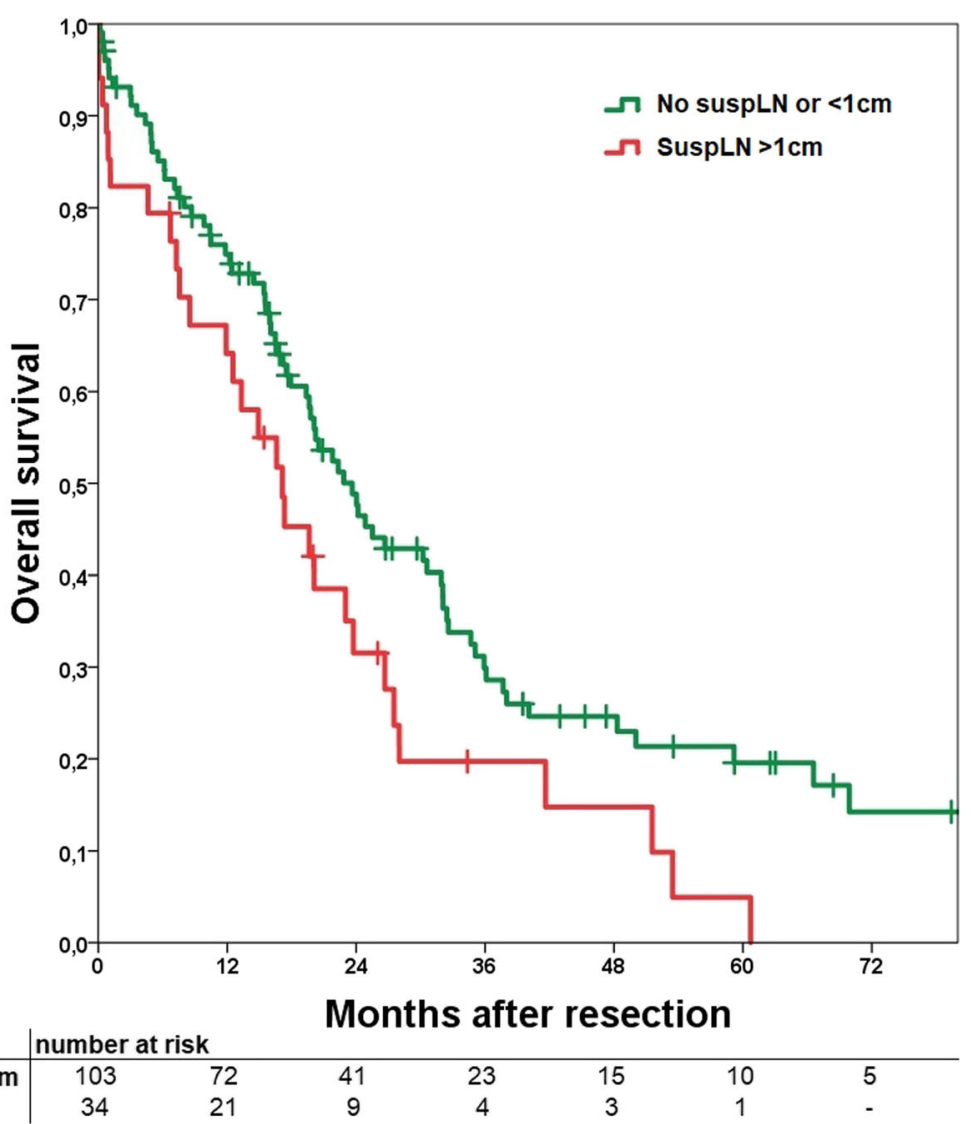

Fig. 2 Kaplan-Meier curve of overall survival comparing a group of no suspicious lymph nodes or a diameter $<1 \mathrm{~cm}$ (No suspLN or $<1 \mathrm{~cm}$ ) and suspicious lymph nodes with a diameter $>1 \mathrm{~cm} . p=0.026$

considerations. In elderly or patients with a moderate state of health with a high risk of morbidity/mortality we would perform frozen section of clinically suspicious distant lymph nodes and resign from resection if positive. In younger patients or ones in good general state of health we would perform resection with extended lymphadenectomy because some of these patients will achieve long-term survival. Different studies within the last decade demonstrated that lymph node metastases are a predictor of poor OS and RFS for ICC keeping in mind that results and significance vary [2-8]. We aimed to demonstrate the relevance of preoperatively assessed lymph nodes via CT or MRI in five different typical lymph node stations regarding resectability, recurrence, OS, and RFS in patients with ICC.

Literature on preoperative evaluation of lymph nodes for ICC is scarce. Analyses of the influence of suspicious lymph nodes on resectability are not available. The ratio of suspLN in the exploration group divided by the total number of suspLN per lymph node station was calculated. A tendency becomes apparent that the likelihood of unresectability increases with suspLN in more distant lymph node stations. The fact that all tumors with suspLN superior to the diaphragm were unresectable because of intraabdominal tumor extension might be falsified due to the small number of patients in this subgroup, but nonetheless it is comprehensible. These patients might be candidates to resign from surgery or at least start with a laparoscopy, which has proven to be effective in ICC to minimize operative trauma and reduce the time until palliative treatment can be initiated [26, 27].

Suspicious lymph nodes in preoperative imaging are not automatically lymph node metastases. First of all it is important to say that lymphadenectomy is discussed intensively for ICC leading to a recommendation of harvesting six lymph nodes [1]. Analyses most often come to the conclusion that the number of metastatic lymph nodes is more important than the number of totally harvested lymph nodes [9-11]. The importance and influence especially of extended lymphadenectomy is not much considered for ICC yet. But for example, in perihilar cholangiocarcinoma it leads to worse long-term outcome and higher morbidity compared to regular lymphadenectomy and does not seem reasonable [28]. It is important to bring to mind that a suspicious lymph node in preoperative imaging is not always harvested 
routinely. Therefore, an inaccuracy remains in comparison of preoperative imaging and final histopathological results. The positive predictive value (PPV) between imaging and histology is not persuasive. Noji and colleagues focussed on this topic (via CT) and found a PPV of $56 \%$ for metastatic lymph nodes if the diameter of a round lymph node exceeded $16 \mathrm{~mm}$ [17]. This applies for MRI as well [29]. Other groups made comparable experiences that suspected lymph nodes are not associated with histopathologically proven metastases [30] or concluded that the preoperative evaluation remains difficult [18]. Park and colleagues showed a higher sensitivity (80\%) and specificity (92.3\%) in predicting lymph node metastases with preoperative PET-CT [31], while Yoh and colleagues were able to show that patients with a low CA19-9 value $(<37 \mathrm{IU} / \mathrm{ml})$, peripheral ICC and no suspicious lymph nodes in preoperative imaging were likely to have no lymph node metastases (false negative rate $2.3 \%$ ) [20]. We harvested a median of five lymph nodes, which gets close to the recommended amount of six in the AJCC/UICC/TNM classification [1].

Presence of cirrhosis influences size and shape of lymph nodes. In our study 12 patients were diagnosed with cirrhosis. In three of these patients we resigned from resection because of incidental finding of a before unknown cirrhosis, nine patients underwent minor resections. Only two of these patients had suspLN in the preoperative imaging, one in the resection and one in the exploration group. Therefore, we think it is safe to say that presence of cirrhosis did not affect our analysis.

Other clinicopathological parameters were also tested with suspicious lymph nodes and $\mathrm{T}$ status showed a significant correlation to $\mathrm{N}$ status while UICC stage significantly correlated with suspLN. That UICC stage and N status were significant as well can be easily explained because N1 automatically leads to an UICC stage of IIIb. Parameters like tumor size, multifocality or number of nodules showed no significant correlation which might have different reasons. On the one hand it is possible that the sample size is too small for example for number of nodules which nearly reaches significance with $p=0.087$. On the other hand, tumor biology might not be defined through tumor size for example. A solitary ICC with a diameter of $8 \mathrm{~cm}$ might be less aggressive than three nodules with largest diameters of $3 \mathrm{~cm}$. But this is prospect of ongoing investigations, not part of this study to answer and might be better understood in the future with other procedures like next generation sequencing (NGS).

SuspLN did not influence tumor recurrence of any kind in our cohort. This is comprehensible with the pattern of recurrence of ICC, which appears most often intrahepatic with only small amounts of extrahepatic or combined intra- and extrahepatic recurrences [13, 32, 33].
Survival analyses regarding suspicious lymph nodes show diverse results. Adachi and colleagues were able to show a significant benefit for the group without suspicious lymph nodes in preoperative imaging (patients with histologically proven lymph node metastases included) [18], while Marubashi and colleagues [30] did neither find an influence on OS nor RFS in patients with or without suspicious lymph nodes. Other articles did not analyse influence on survival. Our data suits perfectly in this diverse picture. For RFS, an influence could only be shown if a cut-off of $1 \mathrm{~cm}$ was used $(p=0.008)$; the same applies for OS $(p=0.026)$. This might show that lymph nodes below a short-axis diameter of $1 \mathrm{~cm}$ are not conclusive at all, even if they are round or with inhomogeneous vascularity. It is also according to our finding that with increasing size of suspicious lymph nodes the likelihood of metastases raises. All lymph nodes $>1.5 \mathrm{~cm}$ had metastatic disease $(\mathrm{N}+)$ except in one patient in interaortocaval position.

Single-center data with a consistent stem of surgeons led to a high homogeneity in decision making and comparable attitude. The number of 187 analysed patients with 137 resections is decent from our point of view. However, this study has several limitations. First of all, we want to address the retrospective design. Because of this it was not possible to react on findings of preoperative imaging and maybe extend lymphadenectomy to get a better picture of suspicion and histopathology. A multi-center study offers more patients and therefore more validity, even if it brings bias and negative features as well. Especially subgroup analyses are lacking of power due to the small number of patients. Another limitation is the correct diagnosis of lymph node metastasis. It is well known, that the correct classification of lymph node metastasis in cholangiocarcinoma and also most other types of cancer can be challenging as already stated above. Therefore, in this project the dedicated imaging analysis was carried out by an experienced investigator applying prespecified objective criteria as stated in the methods section. Nevertheless, misclassifications cannot be avoided. A technique which would have possibly improved detection rates to a certain amount is PET-CT; however this is not routinely performed in this tumor entity and is currently not recommended outside of clinical trials [19].

\section{Conclusions}

In conclusion we were able to demonstrate that suspicious lymph nodes in preoperative imaging have influence on different factors. Resectability is more likely if the patient does not present with suspicious lymph nodes, but even if nodes $>1.5 \mathrm{~cm}$ are detected, resection and complete tumor clearance is still achievable. With a cut-off of suspicious lymph nodes of $1 \mathrm{~cm}$ a significant 
influence on RFS can be seen. The same applies for OS which is affected at a cut-off of $1 \mathrm{~cm}$ as well. It is important to classify these results in the correct way. Although suspicious lymph nodes in the preoperative imaging may be associated with a worse prognosis, in a considerable number of cases they are false positive. Explorative laparoscopy should be considered, especially if suspicious lymph nodes in distant localisations are detected in preoperative imaging to reduce operative trauma in case of irresectability. Surgery is the only chance of cure and therefore suspicious lymph nodes should be no reason to resign from surgery in most cases, because complete resection can still be achieved.

\section{Abbreviations \\ CT: Computed tomography; ICC: Intrahepatic cholangiocarcinoma; IQR: Interquartile range; MRI: Magnetic resonance imaging; OS: Overall survival; PET-CT: Positron emission tomography-computed tomography; RFS: Recurrence-free survival; suspLN: Suspicious lymph nodes}

\section{Acknowledgments}

Not Applicable.

\section{Authors' contributions}

All authors critically revised the manuscript, approved the final version to be published, and agree to be accountable for all aspects of the work. FB: concept and design of the study, data acquisition, statistical analysis, draft of the manuscript, critical revision. FH: data acquisition. LM: data acquisition. JB: data acquisition. MH-L: data acquisition, follow-up. RK: draft of the manuscript, critical revision. HL: concept and design of the study, draft of the manuscript, critical revision.

\section{Funding}

No funding was obtained for this study.

\section{Availability of data and materials}

The datasets used and analyzed during the current study are available from the corresponding author on reasonable request.

\section{Ethics approval and consent to participate}

This article analysis retrospective data and does not contain any studies with human participants or animals performed by any of the authors. All patients signed informed consent that data and follow-up will be collected anonymously and is potentially used for scientific analysis. Regarding to the regulations of the federal state law (state hospital law \$36 \& \$37) and the independent ethics committee of Rhineland-Palatinate, no ethical approval was necessary for this study

\section{Consent for publication}

Not applicable.

\section{Competing interests}

The authors declare that they have no financial or non-financial competing interests.

\section{Author details}

'Department of General, Visceral and Transplant Surgery, University Medical Center of the Johannes Gutenberg-University Mainz, Langenbeckst. 1, 5513 Mainz, Germany. ${ }^{2}$ Department of Diagnostic and Interventional Radiology, University Medical Center of the Johannes Gutenberg-University Mainz, Mainz, Germany,
Received: 20 January 2020 Accepted: 26 March 2020

Published online: 15 April 2020

\section{References}

1. Brierley J, Gospodarowicz M, Wittekind C. International union against Cancer. TNM classification of malignant Tumours. 8th ed. Oxford: Wiley Blackwell; 2017.

2. de Jong MC, Nathan H, Sotiropoulos GC, Paul A, Alexandrescu S, Marques $H$, et al. Intrahepatic cholangiocarcinoma: an international multi-institutional analysis of prognostic factors and lymph node assessment. J Clin Oncol. 2011:29(23):3140-5.

3. Sakamoto Y, Kokudo N, Matsuyama Y, Sakamoto M, Izumi N, Kadoya M, et al. Proposal of a new staging system for intrahepatic

cholangiocarcinoma: analysis of surgical patients from a nationwide survey of the liver Cancer study Group of Japan. Cancer. 2016;122(1):61-70.

4. Bektas H, Yeyrek C, Kleine M, Vondran FW, Timrott K, Schweitzer N, et al. Surgical treatment for intrahepatic cholangiocarcinoma in Europe: a single center experience. J Hepatobiliary Pancreat Sci. 2015;22(2):131-7.

5. Wang Y, Li J, Xia Y, Gong R, Wang K, Yan Z, et al. Prognostic nomogram for intrahepatic cholangiocarcinoma after partial hepatectomy. J Clin Oncol. 2013;31(9):1188-95.

6. Farges O, Fuks D, Boleslawski E, Le Treut YP, Castaing D, Laurent A, et al. Influence of surgical margins on outcome in patients with intrahepatic cholangiocarcinoma: a multicenter study by the AFC-1HCC-2009 study group. Ann Surg. 2011;254(5):824-9 discussion 30.

7. Lang H, Sotiropoulos GC, Sgourakis G, Schmitz KJ, Paul A, Hilgard P, et al. Operations for intrahepatic cholangiocarcinoma: single-institution experience of 158 patients. J Am Coll Surg. 2009;208(2):218-28.

8. Guglielmi A, Ruzzenente A, Campagnaro T, Pachera S, Valdegamberi A, Nicoli $P$, et al. Intrahepatic cholangiocarcinoma: prognostic factors after surgical resection. World J Surg. 2009;33(6):1247-54.

9. Bagante F, Spolverato G, Weiss M, Alexandrescu S, Marques HP, Aldrighetti $\mathrm{L}$, et al. Assessment of the lymph node status in patients undergoing liver resection for intrahepatic Cholangiocarcinoma: the new eighth edition AJCC staging system. J Gastrointest Surg. 2018;22(1):52-9.

10. Jutric Z, Johnston WC, Hoen HM, Newell PH, Cassera MA, Hammill CW, et al. Impact of lymph node status in patients with intrahepatic cholangiocarcinoma treated by major hepatectomy: a review of the National Cancer Database. HPB (Oxford). 2016;18(1):79-87.

11. Guglielmi A, Ruzzenente A, Campagnaro T, Valdegamberi A, Bagante F, Bertuzzo F, et al. Patterns and prognostic significance of lymph node dissection for surgical treatment of perihilar and intrahepatic cholangiocarcinoma. J Gastrointest Surg. 2013;17(11):1917-28.

12. Dhanasekaran R, Hemming AW, Zendejas I, George T, Nelson DR, SoldevilaPico C, et al. Treatment outcomes and prognostic factors of intrahepatic cholangiocarcinoma. Oncol Rep. 2013;29(4):1259-67.

13. Bartsch F, Paschold M, Baumgart J, Hoppe-Lotichius M, Heinrich S, Lang H. Surgical resection for recurrent intrahepatic cholangiocarcinoma. World J Surg. 2019;43(4):1105-16.

14. Choi SB, Kim KS, Choi JY, Park SW, Choi JS, Lee WJ, et al. The prognosis and survival outcome of intrahepatic cholangiocarcinoma following surgical resection: association of lymph node metastasis and lymph node dissection with survival. Ann Surg Oncol. 2009;16(11):3048-56.

15. Yamamoto M, Takasaki K, Otsubo T, Katsuragawa H, Katagiri S. Recurrence after surgical resection of intrahepatic cholangiocarcinoma. J Hepato-BiliaryPancreat Surg. 2001;8(2):154-7.

16. Jonas S, Thelen A, Benckert C, Biskup W, Neumann U, Rudolph B, et al. Extended liver resection for intrahepatic cholangiocarcinoma: a comparison of the prognostic accuracy of the fifth and sixth editions of the TNM classification. Ann Surg. 2009;249(2):303-9.

17. Noji T, Kondo S, Hirano S, Tanaka E, Suzuki O, Shichinohe T. Computed tomography evaluation of regional lymph node metastases in patients with biliary cancer. Br J Surg. 2008;95(1):92-6

18. Adachi T, Eguchi S, Beppu T, Ueno S, Shiraishi M, Okuda K, et al. Prognostic impact of preoperative lymph node enlargement in intrahepatic Cholangiocarcinoma: a multi-institutional study by the Kyushu study Group of Liver Surgery. Ann Surg Oncol. 2015;22(7):2269-78.

19. $\mathrm{Hu} \mathrm{JH}$, Tang JH, Lin CH, Chu YY, Liu NJ. Preoperative staging of cholangiocarcinoma and biliary carcinoma using 18F-fluorodeoxyglucose positron emission tomography: a meta-analysis. J Investig Med. 2018;66(1): 52-61. 
20. Yoh T, Hatano E, Seo S, Terajima H, Uchida Y, Taura K, et al. Preoperative criterion identifying a low-risk group for lymph node metastasis in intrahepatic cholangiocarcinoma. J Hepatobiliary Pancreat Sci. 2018;25(6): 299-307.

21. Eisenhauer EA, Therasse P, Bogaerts J, Schwartz LH, Sargent D, Ford R, et al. New response evaluation criteria in solid tumours: revised RECIST guideline (version 1.1). Eur J Cancer. 2009;45(2):228-47.

22. Schwartz LH, Bogaerts J, Ford R, Shankar L, Therasse P, Gwyther S, et al. Evaluation of lymph nodes with RECIST 1.1. Eur J Cancer. 2009;45(2):261-7.

23. Mao $Y$, Hedgire $S$, Harisinghani M. Radiologic assessment of lymph nodes in oncologic patients. Current Radiology Reports. 2013;2(2):36.

24. Punt CJ, Buyse M, Kohne CH, Hohenberger P, Labianca R, Schmoll HJ, et al. Endpoints in adjuvant treatment trials: a systematic review of the literature in colon cancer and proposed definitions for future trials. J Natl Cancer Inst. 2007;99(13):998-1003.

25. Bartsch F, Baumgart J, Hoppe-Lotichius M, Schmidtmann I, Heinrich S, Lang $\mathrm{H}$. Visceral infiltration of intrahepatic cholangiocarcinoma is most prognostic after curative resection - Retrospective cohort study of 102 consecutive liver resections from a single center. Int J Surg. 2018:55:193-200.

26. D'Angelica M, Fong Y, Weber S, Gonen M, DeMatteo RP, Conlon K, et al. The role of staging laparoscopy in hepatobiliary malignancy: prospective analysis of 401 cases. Ann Surg Oncol. 2003;10(2):183-9.

27. Goere D, Wagholikar GD, Pessaux P, Carrere N, Sibert A, Vilgrain V, et al. Utility of staging laparoscopy in subsets of biliary cancers : laparoscopy is a powerful diagnostic tool in patients with intrahepatic and gallbladder carcinoma. Surg Endosc. 2006;20(5):721-5.

28. Hakeem AR, Marangoni G, Chapman SJ, Young RS, Nair A, Hidalgo EL, et al. Does the extent of lymphadenectomy, number of lymph nodes, positive lymph node ratio and neutrophil-lymphocyte ratio impact surgical outcome of perihilar cholangiocarcinoma? Eur J Gastroenterol Hepatol. 2014;26(9): 1047-54.

29. Songthamwat M, Chamadol N, Khuntikeo N, Thinkhamrop J, Koonmee S, Chaichaya $\mathrm{N}$, et al. Evaluating a preoperative protocol that includes magnetic resonance imaging for lymph node metastasis in the Cholangiocarcinoma screening and care program (CASCAP) in Thailand. World J Surg Oncol. 2017;15(1):176.

30. Marubashi S, Gotoh K, Takahashi H, Ohigashi H, Yano M, Ishikawa O, et al. Prediction of the postoperative prognosis of intrahepatic cholangiocarcinoma (ICC): importance of preoperatively- determined anatomic invasion level and number of tumors. Dig Dis Sci. 2014;59(1):201-13.

31. Park TG, Yu YD, Park BJ, Cheon GJ, Oh SY, Kim DS, et al. Implication of lymph node metastasis detected on 18F-FDG PET/CT for surgical planning in patients with peripheral intrahepatic cholangiocarcinoma. Clin Nucl Med. 2014;39(1):1-7.

32. Spolverato G, Kim Y, Alexandrescu S, Marques HP, Lamelas J, Aldrighetti L, et al. Management and outcomes of patients with recurrent intrahepatic Cholangiocarcinoma following previous curative-intent surgical resection. Ann Surg Oncol. 2016;23(1):235-43.

33. Ercolani G, Vetrone G, Grazi GL, Aramaki O, Cescon M, Ravaioli M, et al. Intrahepatic cholangiocarcinoma: primary liver resection and aggressive multimodal treatment of recurrence significantly prolong survival. Ann Surg. 2010;252(1):107-14.

\section{Publisher's Note}

Springer Nature remains neutral with regard to jurisdictional claims in published maps and institutional affiliations.

\section{Ready to submit your research? Choose BMC and benefit from}

- fast, convenient online submission

- thorough peer review by experienced researchers in your field

- rapid publication on acceptance

- support for research data, including large and complex data types

- gold Open Access which fosters wider collaboration and increased citations

- maximum visibility for your research: over $100 \mathrm{M}$ website views per year

At BMC, research is always in progress.

Learn more biomedcentral.com/submissions 